\title{
A case study on severe damage at a tunnel in serpentinite rock mass
}

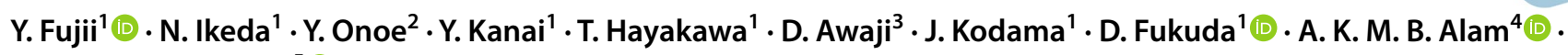

A. B. N. Dassanayake ${ }^{5}$

Received: 13 August 2021 / Accepted: 13 December 2021

Published online: 21 December 2021

(c) The Author(s) 2021 OPEN

\begin{abstract}
Face squeezing, floor heave, and buckling of invert were found after a 10-day holiday in 2014 around the serpentinite face of a tunnel in Hokkaido, Japan. The damage continued for over 2 months, extending $400 \mathrm{~m}$ toward the entrance causing a massive roof fall. The tunnel was excavated again with a circular section and extra-thick shotcrete, and the face had crossed the damaged part 6 years after the damage occurred. Uniaxial and triaxial compression tests were carried out to obtain the mechanical properties of the serpentinite to clarify the severe damage mechanism at the tunnel. The main experimental findings are as follows. The uniaxial compressive strength of the serpentinite samples was very low, and the ratio of the strength to the estimated overburden pressure was extremely low. The parameter $n$ indicated that the time-dependent deformation of the serpentinite was not large but the same as ordinary rocks. All specimens showed strain-hardening in the triaxial compression test, and the friction angle was very low by the brucite content. Only primary creep was observed in the multistage triaxial creep test. The pressure on the shotcrete from rock mass for the damaged tunnel was enough to cause creep deformation and failure of shotcrete. From the above findings, designing the concrete lining that can support the earth and water pressure is recommended for tunnel excavation in such a weak serpentinite rock mass, particularly with a very low friction angle by brucite.
\end{abstract}

\section{Highlights}

- Face squeezing, floor heave, and buckling of invert were found after a 10-day holiday around the serpentinite face in Hokkaido, Japan.

- The time-dependent deformation of the serpentinite was not large but the same as ordinary rocks.
- All specimens showed strain-hardening in the triaxial compression test, and the friction angle was very low by the brucite content.

- Only primary creep was observed in the multistage triaxial creep test.

- The severe damage to the tunnel was not a brittle creep failure of the serpentinite rock mass itself but the shotcrete lining.

Keywords Serpentinite $\cdot$ Severely damaged tunnel $\cdot$ Uniaxial test $\cdot$ Triaxial test $\cdot$ Creep test $\cdot$ Brucite

Y. Fujii, fujii6299@frontier.hokudai.ac.jp | ${ }^{1}$ Rock Mechanics Laboratory, Hokkaido University, N13W8, Sapporo 060-8628, Japan. ${ }^{2}$ Kobe Steel, Ltd., 2-2-4, Kaigan St., Wakihama, Kobe 651-8585, Japan. ${ }^{3}$ Shimizu Corporation, 2-16-1, Kyobashi, Tokyo 104-8370, Japan. ${ }^{4}$ Military Institute of Science and Technology, Dhaka 1216, Bangladesh. ${ }^{5}$ Department of Earth Resources Engineering, University of Moratuwa, Moratuwa 10400, Sri Lanka. 


\section{Introduction}

Face squeezing, floor heave, and buckling of invert were found after a 10-day New Year holiday in 2014 around the serpentinite face of a tunnel in the central axis of Hokkaido, Japan. The damage continued over 2 months, extending $400 \mathrm{~m}$ toward the entrance causing a massive roof fall. The tunnel was excavated again with a circular section and extra-thick shotcrete, and the face had just crossed the damaged part in June 2020; over 6 years have passed since the damage occurred.

Case studies on the deformation of serpentinite tunnels are not hit in the Web of Science database, although severe deformation has been experienced at soft rock tunnels worldwide, and many papers have been published (ex. [1], [2]. The lack of publication may indicate that tunnel excavation in serpentinite is difficult and tends to be avoided outside Japan and empirically managed in Japan. However, serpentinite rock masses are often encountered in tunnel constructions in that area, and they have caused various damages. Knowing the damage mechanism of the tunnel may be beneficial for ensuring safety and saving time and cost of tunnel excavations in similar rock masses. Therefore, the serpentinite's mechanical properties were investigated experimentally by uniaxial and triaxial compression tests, which would play a significant role in the damage mechanisms.

The damages will be described first with the monitoring results of the vertical displacement and the convergence at the tunnel. The results of rock testing will be shown next. Finally, the severe tunnel damage mechanisms will be discussed based on the results of the measurement and experiments.

\section{Severe damage}

As shown in Fig. 1, the rock masses for the 4686-m-long tunnel consist of Cretaceous mudstone, serpentinite of unknown geological age, Jurassic-Cretaceous basaltic pillow lava, Jurassic-Cretaceous hyaloclastite, Jurassic-Cretaceous sandstone, Jurassic-Cretaceous mudstone, Jurassic-Cretaceous sandstone, and Cretaceous mudstone-sandstone alternation from left to right. The excavation was carried out from both sides; the left face reached the serpentinite part $260 \mathrm{~m}$ deep, causing severe damage.

Four-ton hydraulic breakers excavated the left face of the serpentinite part, and the sectional area of the tunnel ranged from 125 to $131 \mathrm{~m}^{2}$ with the inner radius of the lining $(R)$ for the upper section being $5.75 \mathrm{~m}$. The facebolting and AGF (All Ground Fastened) methods were adopted to improve the stability of the face and the roof of the tunnel, respectively. Twenty-two standard rock bolts were installed on the sidewall. The double shotcrete (300 mm $+300 \mathrm{~mm}$ thick) with steel arches was adopted. The inner radius of the invert was initially designed as $3 R$ but changed to $1.5 R$ to increase the floor stability. The invert was installed $7 \mathrm{~m}$ behind the face (earlier than usual) to enhance the stability of the entire section.

The severe damage, as shown in Fig. 2, occurred as follows:

I Face squeezing, floor heave, and buckling of invert were noticed on Jan. 6,2014 , following the New Year holidays from Dec. 27, 2013, to Jan. 5, 2014.

II Within a few days, the floor heave and deformation of shotcrete extended from the face to $180 \mathrm{~m}$ behind the face.

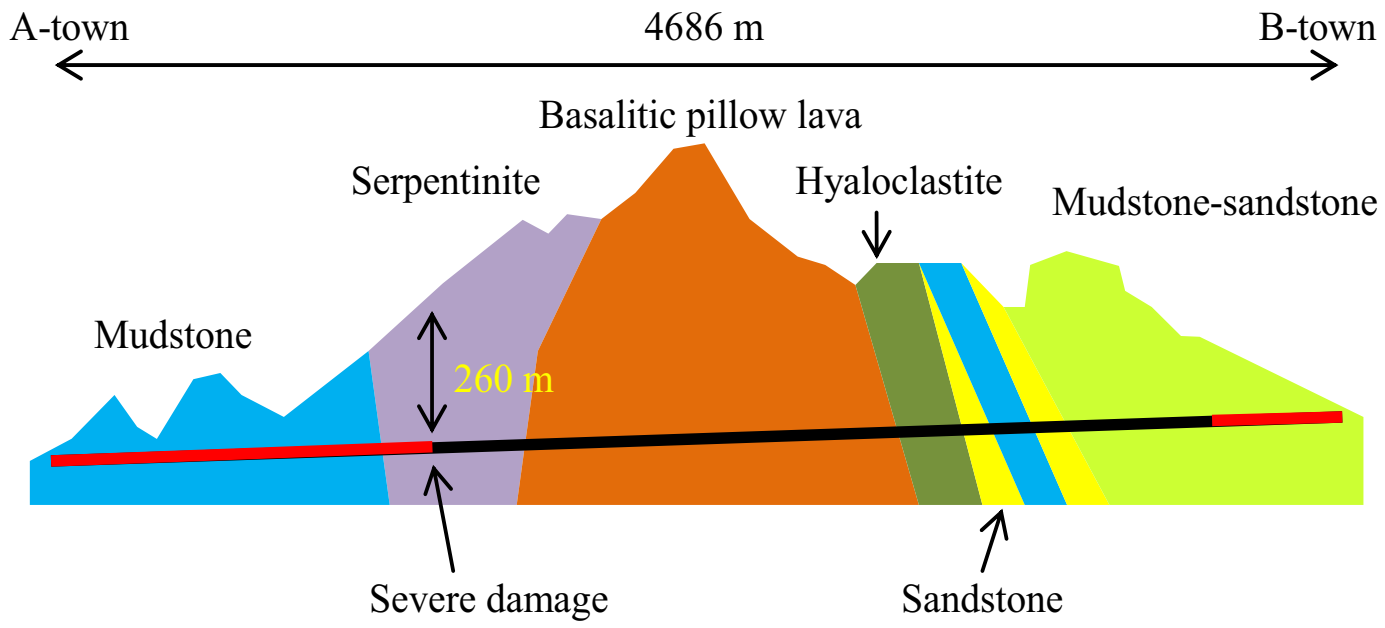

Fig. 1 Simplified geologic sectional view (after [12]) 


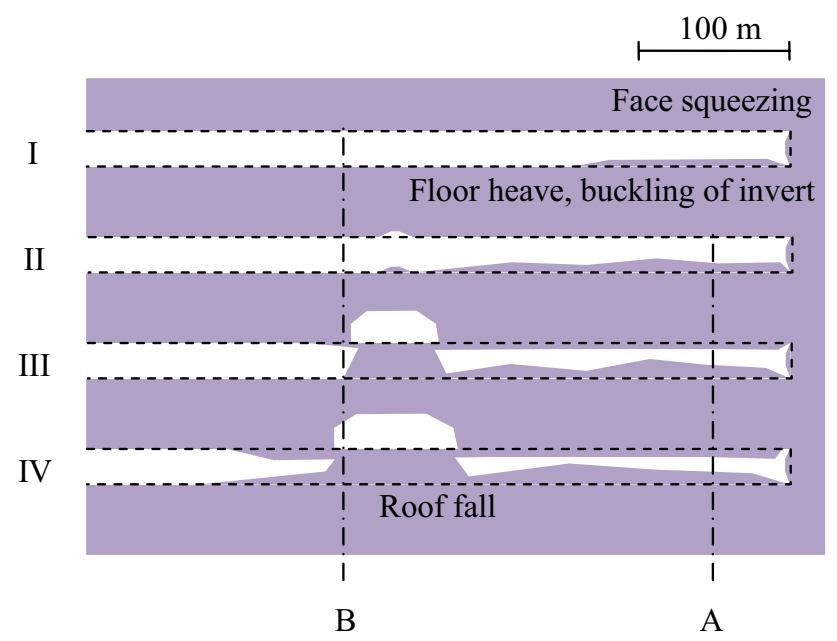

Fig. 2 Schematic figure of the severe deformation (after [3])

III Fifty days after the first damage detection, a roof collapse occurred at $250 \mathrm{~m}$ behind the face.

IV The floor heave and deformation of the shotcrete gradually extended from the point of roof fall to 150 $m$ toward the tunnel entrance.

The convergence of the tunnel was calculated from the monitored displacements of the shotcrete, as shown in Fig. 3. The high rates of downward vertical displacement and the shrinking convergence occurred at $56.8 \mathrm{~m}$ behind the face after the excavation, and the rate decreased with time, as shown in Fig. 4. However, they increased during the New Year holidays, indicating the beginning of the damage, and the increase persisted. The measurement of the displacement became impossible upon the detection of the damage.

The displacements and the convergences, $296.5 \mathrm{~m}$ behind the face at the entrance side edge of the roof collapse, had been fully converged before the New Year holidays, as shown in Fig. 5. Even a buoyant behavior can be found in the vertical displacement. However, with the

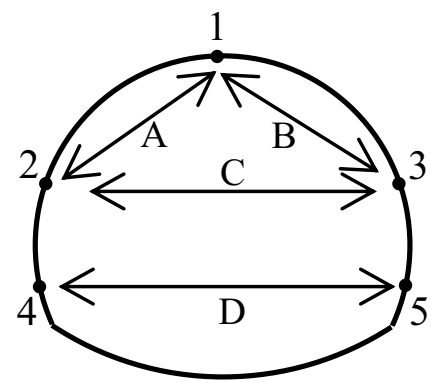

Fig. 3 Monitoring section for the displacements $1-5$ and the definition of convergences $A-D$, viewing from 10 the entrance to the face

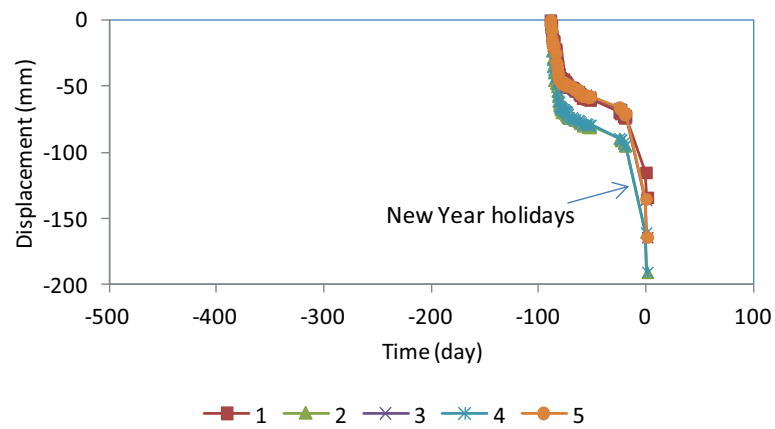

(a) Vertical displacement

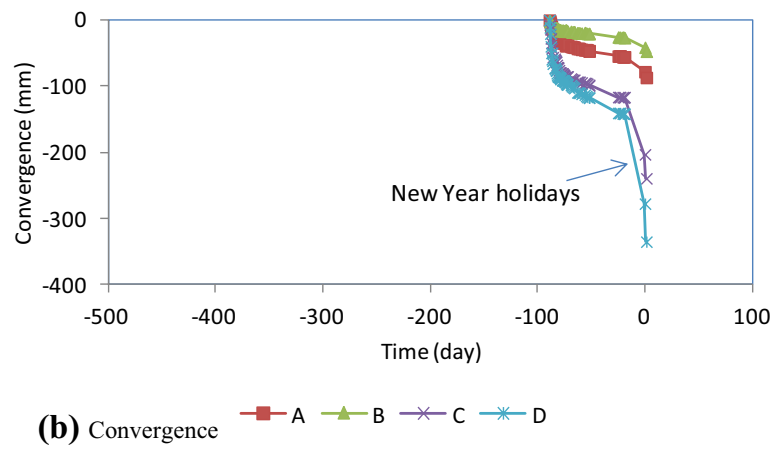

Fig. 4 Monitored deformation at the section A (56.8 $\mathrm{m}$ behind the face). Negative values indicate $\mathbf{a} 17$ downward and $\mathbf{b}$ contraction. Time is set to zero at the discovery of the damage (Jan. 6, 2014)

damage following the New Year holidays, the displacements and the convergences increased at almost a constant rate until the roof collapsed, making measurement impossible.

A circular pilot tunnel was excavated into the severely damaged area supported by $400-\mathrm{mm}$-thick shotcrete and steel arches [3]. The pilot tunnel was enlarged to the main tunnel, which was also circular, with a radius of $7.55 \mathrm{~m}$ and supported by $400 \mathrm{~mm}$ (outer) $+400 \mathrm{~mm}$ (middle) $+350 \mathrm{~mm}$ (inner) thick triple shotcrete with steel arches. In June 2020, after 6 years since the damage, the face of the main tunnel had just safely passed the serpentinite part,

\section{Rock sample}

Nearly horizontal $50 \mathrm{~mm} \phi$ holes, approximately $25 \mathrm{~m}$ long, were drilled from the sidewall of the new main tunnel around the roof collapse site, at an angle of 10-26 degrees to the tunnel axis. The rock cores, which were long enough and not severely fractured, were immediately stored in plastic bags. They were divided into massive, foliated, clayish, and very hard samples, as shown in Fig. 6. According to the XRD (X-ray diffraction) analysis shown in Table 1, the very hard samples contained a moderate 


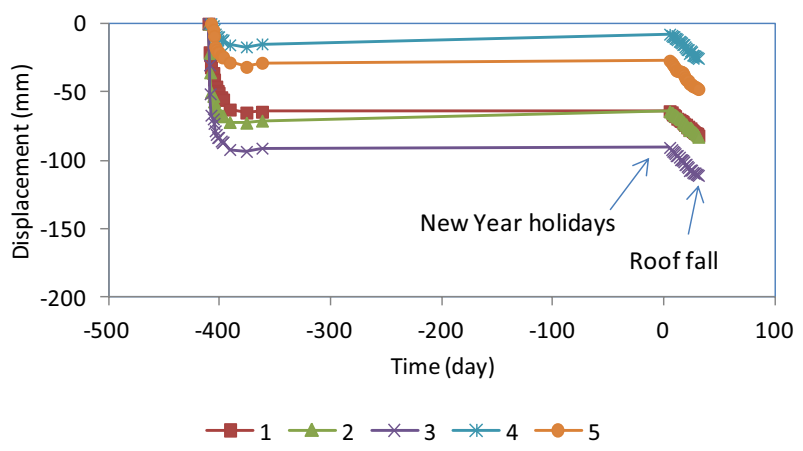

(a) Vertical displacement

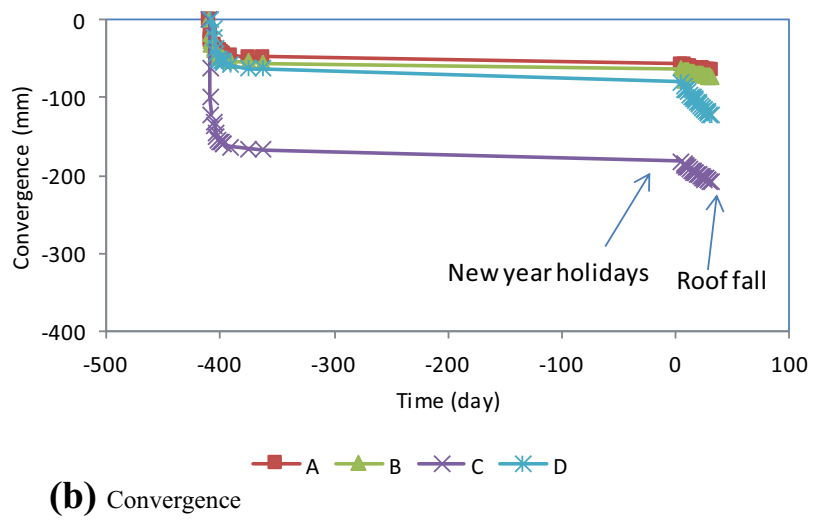

Fig. 5 Monitored deformation at the section B ( $296.5 \mathrm{~m}$ behind the face and the edge at the entrance side of 24 the roof fall). Negative values indicate $\mathbf{a}$ downward and $\mathbf{b}$ contraction. Time is set to zero at the discovery 25 of the damage (Jan. 6, 2014)

amount of forsterite and magnetite and were not identified as serpentinite. They did not seem to have played a significant role in the severe damage of the tunnel. Hence, rock testings were not conducted.

In contrast, the massive samples contain a moderate amount of chrysotile and lizardite and a small amount of brucite, as shown in Table 1. Original minerals were mostly serpentinized, and neither olivine nor pyroxene was present. The clayish samples also contain much chrysotile and lizardite, as shown in Table 1, and would be formed by the massive part's crushing.

\section{Uniaxial compression tests}

\subsection{Alternating axial strain rates}

The cores were cut at ca. 100-mm-long specimens, just before the tests. Water was not used during cutting to avoid damage to the specimens. Lightweight polyethylene endpieces were used since the specimens were very weak and could be broken by the weight of usual stainless steel endpieces. The specimen was covered by a thin polyethylene tube to avoid drying. Axial and lateral strains were calculated by dividing the stroke by the specimen length and the radial deformation by the specimen diameter. Since it was difficult to attach extensometers or put strain gauges on the soft surface of the specimens, the radial deformation was measured by dial gauges with plastic targets attached to the side of the specimen by rubber bands. The deformation of the 250-kN screw-type loading frame is negligible since the load was very low.

Strain rates of $10^{-5} \mathrm{~s}^{-1}$ and $10^{-4} \mathrm{~s}^{-1}$ were alternately applied [4] by every $0.25 \%$ axial strain to study the strain rate dependency of strength. The room temperature was kept at $295 \mathrm{~K}$ by an air conditioner. After the test, specimen mass was measured before and after drying in an oven at $353 \mathrm{~K}$ for more than $24 \mathrm{~h}$ to calculate water content.

The specimens showed mild strain-softening behaviors, as shown in Fig. 7. The UCS (uniaxial compressive strength) for the higher and lower strain rates could be read from the stress-strain curves. The UCS of the ten specimens varies widely between 16 and $194 \mathrm{kPa}$, as shown in Fig. 8. The effective overburden pressure at $260 \mathrm{~m}$ depth can roughly be estimated as $3.4 \mathrm{MPa}$, assuming $23 \mathrm{kN} / \mathrm{m}^{3}$ saturated unit volume weight and the water table at the ground surface. The ratio of UCS to the overburden pressure is extremely low in the range of $0.0047-0.057$. There seems to be no apparent difference in the clayish, foliated, and massive specimens, as shown in Fig. 8. However, it should be noted that many clayish parts were highly fragile and could not be used as specimens. Hence, the strength obtained in the clayish specimens would be the highest value.

The parameter $n$ for the strain rate dependency of strength shown in Fig. 9 can be calculated as

$n=\Delta \log (\mathrm{d} \varepsilon / \mathrm{d} t) / \Delta \log \sigma_{\max }-1$

The smaller the parameter $n$ is, the stronger the strain rate dependency is. The parameter $n$ is also called the stress corrosion index, despite that the viscous deformation of clay minerals can also cause creep deformation and time dependency in strength, other than subcritical crack growth [5] by the stress corrosion [6]. The stress corrosion index can be estimated as the slope of log (Mode I stress intensity factor) - log (crack velocity) plot taking the former as the $x$-and the latter as the $y$-axis. This plot is obtained for the subcritical crack growth by the double torsion test [7].

In the double torsion method, the parameter $n$ is given by a series of data generated due to subcritical crack growth during stress relaxation from a plate test specimen. The parameter $n$ is usually obtained for compression 
Fig. 6 Examples of the serpentinite specimens

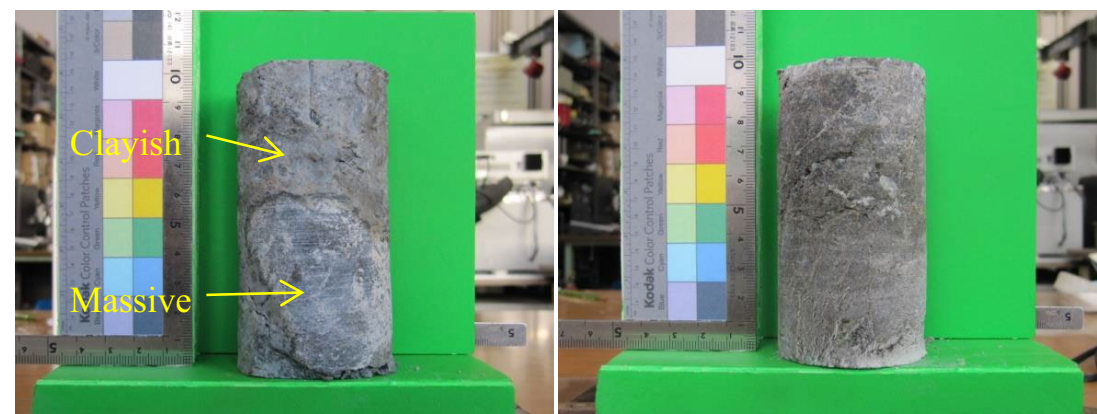

(a) Massive and clayish (os01)

(b) Foliated (os08)

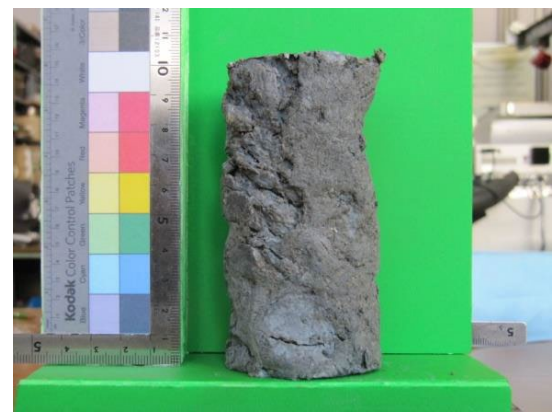

(c) Clayish (os03)

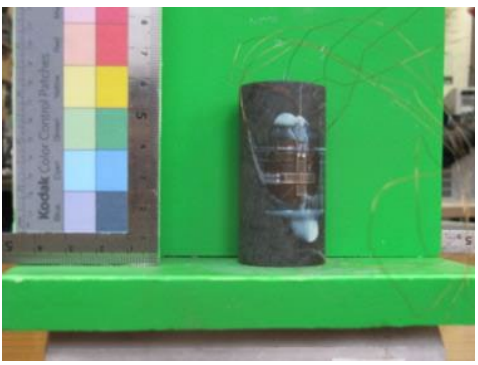

(d) Very hard

Table 1 XRD results (Ant: antigorite, Chr: chrysotile, Liz: lizardite, Br: brucite, 1 For: forsterite, Mt: magnesite, $2++++$ : Very abundant, +++ : Abundant, + +: Moderate, + : Little, -: None)

\begin{tabular}{|c|c|c|c|c|c|c|}
\hline Sample & Ant & Chr & Liz & $\mathrm{Br}$ & For & Mt \\
\hline Massive & - & ++ & ++ & + & - & - \\
\hline Clayish & - & +++ & +++ & - & - & - \\
\hline Very hard & ++++ & ++++ & - & +++ & ++ & ++ \\
\hline
\end{tabular}

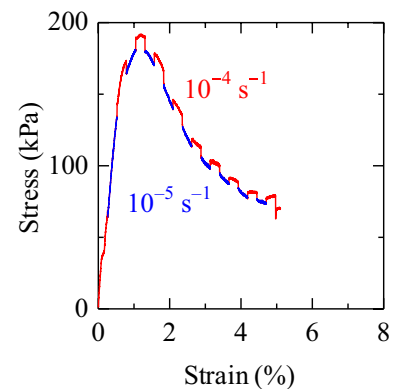

(a)

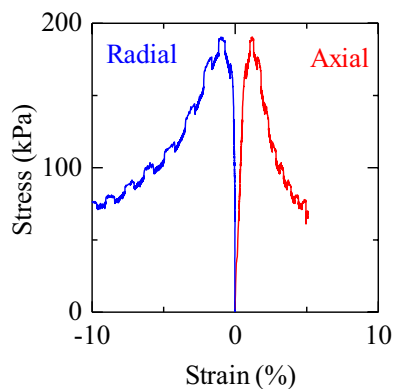

(b)
Fig. 7 Example of stress-strain curves in uniaxial compression test (os08); a digital recorded axial strain 35 and $\mathbf{b}$ analog recorded axial and radial strains

tests by Eq. (1) plotting strength data from many specimens at various strain rates, as shown in Fig. 9. However, the parameter $n$ can be obtained from the corresponding peak stress values for the two or more strain rates from one specimen using the alternating strain rates without being affected by the heterogeneity of specimens.

The calculated $n$-values are also widely distributed between 38 and 122, as shown in Fig. 10. However, seven of the ten data are distributed between 38 and 55. The correlation coefficients for the regression lines concerning UCS and the water content are 0.21 and 0.11 , respectively, not showing a strong positive correlation with UCS or the water content.

\subsection{Creep}

The experimental setup was like the alternative axial strain rate test. Considering the significant scattering in the strength, creep stress values were not prescribed in advance. Instead, axial loading was carried out at $10^{-4} \mathrm{~s}^{-1}$, and the control mode was manually switched to the 


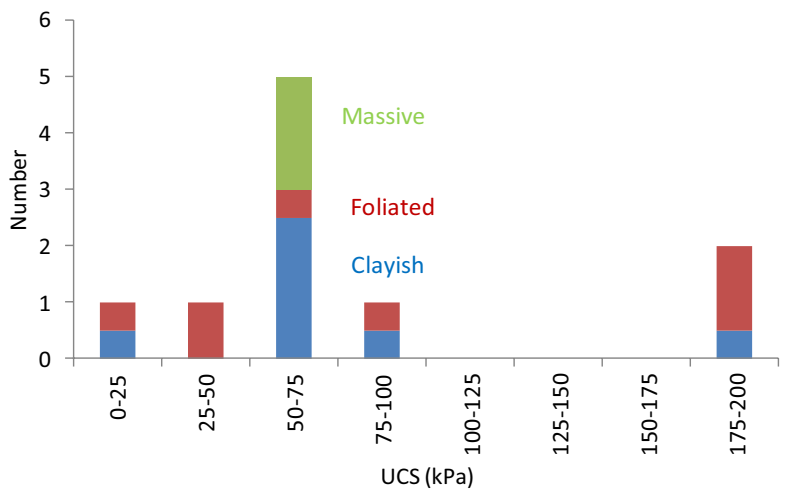

(a) $10^{-5} \mathrm{~s}^{-1}$

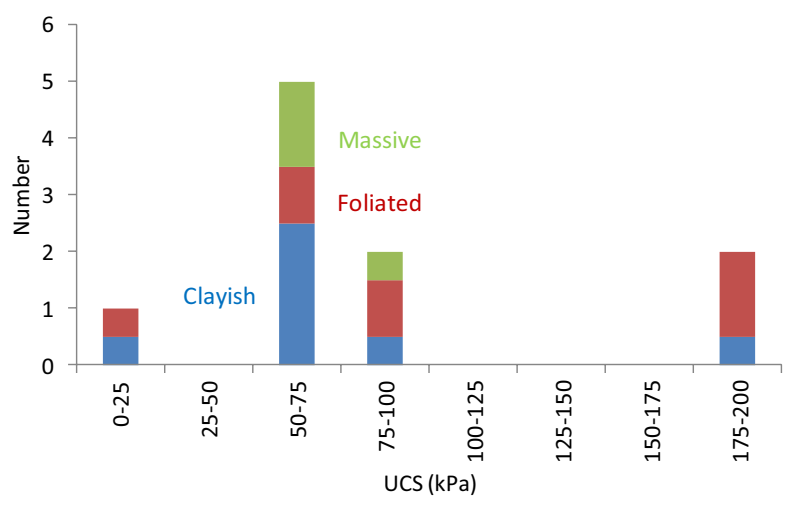

(b) $10^{-4} \mathrm{~s}^{-1}$

Fig. 8 Distribution of UCS. A mixed specimen of A and B was counted as $0.5 \mathrm{~A}$ and $0.5 \mathrm{~B}$

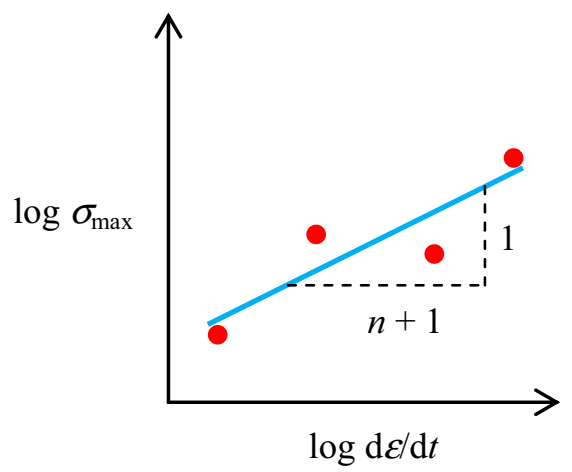

Fig. 9 Calculation of $n$

constant axial stress as the slope of the axial stress-strain curve became gentle, and it seemed that a compressive failure was approaching.

Several specimens failed while the axial stress was being increased. However, the creep behavior for two

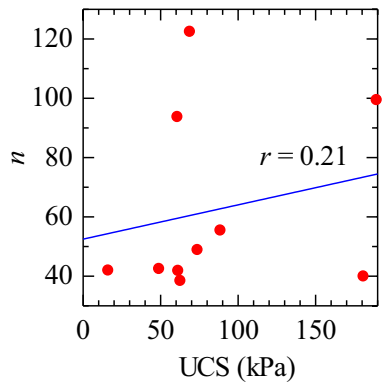

(a)

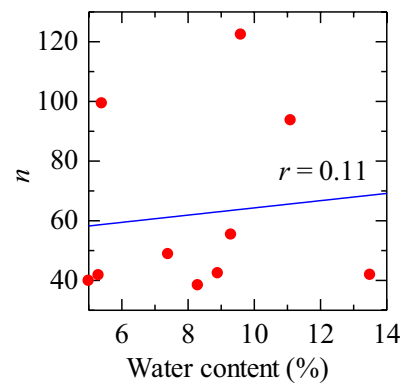

(b)
Fig. 10 Relationship between $n$ and (a) UCS $(\mathrm{d} \varepsilon / \mathrm{d} t=10-5(\mathrm{~s}-1))$ or (b) bater content

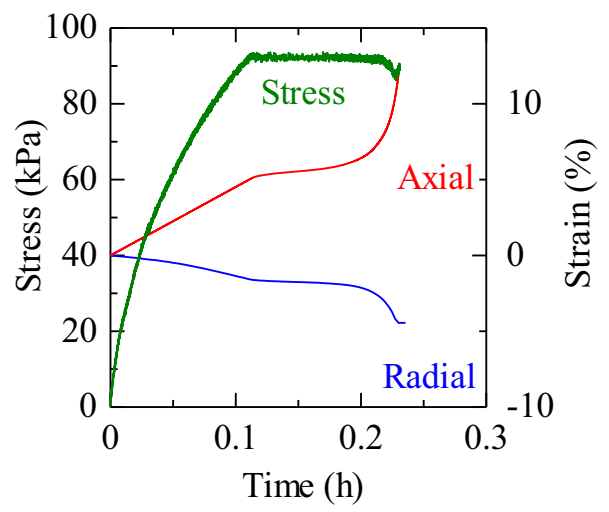

Fig. 11 Example of the results of the uniaxial creep test

specimens was observed until the secondary creep and for another two specimens until creep failure. An example of strain behavior is shown in Fig. 11. Although the primary creep is unclear, the secondary and tertiary creep can be observed. The axial stress was so small that it slightly decreased during the tertiary creep, caused by the loading system's control ability limitation. Generally, the time to failure should increase with decreasing the creep stress. However, this trend was not observed by the significant scatter in the specimen strength, even taking the logarithm for the creep stress as shown in Fig. 12a. On the other hand, the trend can be seen by taking the axial strain values at the beginning of the creep control and even better if the lateral strain values are taken as shown in Fig. 12b, as suggested by Fujii et al. [8].

\section{Triaxial compression tests}

\subsection{Alternating strain rates}

The specimens were prepared in the same manner as the uniaxial test, and the side of the specimen was wrapped 


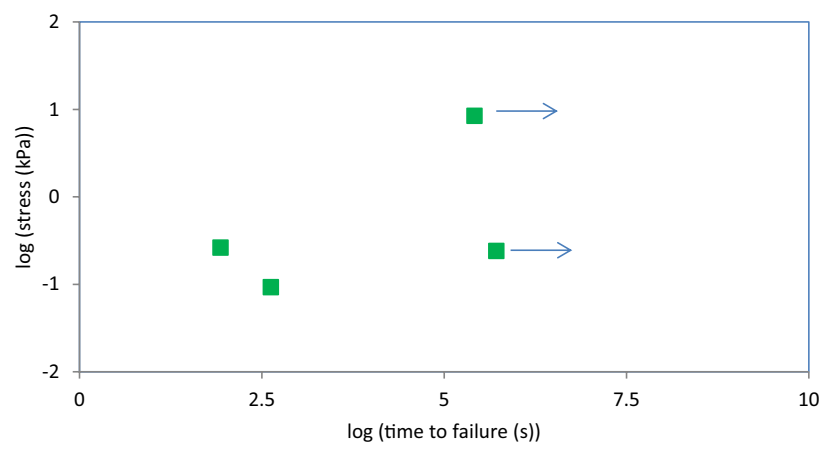

(a) Creep stress vs. time to failure

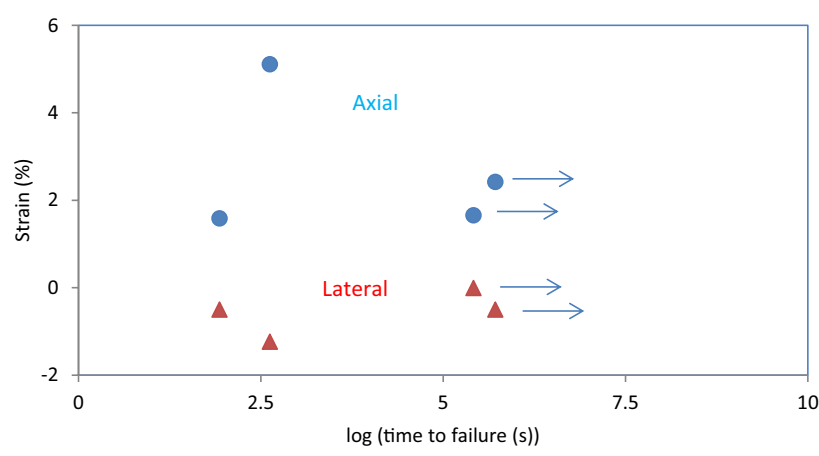

(b) Strain at the beginning of the creep control vs. time to failure

Fig. 12 Time to failure in the uniaxial creep test. The arrows denote that the specimens did not fail

with filter paper to accelerate drainage. The specimen was jacketed by a heat shrinkable tube with stainless steel endpieces and was set in a triaxial vessel. The test was conducted on the same loading frame as the uniaxial tests. A syringe pump applied the confining pressure, and the pore water was open to the atmosphere at both ends. The filter paper was also placed between the specimen ends and the endpieces to prevent fine particles from being washed out. The paper was layered typically ten times to prevent breakage. The axial strain was calculated by dividing the stroke by the specimen length. The aerial strain was defined as the change in the sectional area divided by the initial sectional area and calculated by dividing the drainage volume of the confining water by the specimen volume. A half the aerial strain was regarded as the lateral strain.

The confining pressure was set at $1.7,3.4$, or $6.8 \mathrm{MPa}$. They are $1 / 2,1$, or 2 times the effective overburden pressure estimated as above. Each specimen was consolidated for $8 \mathrm{~h}$. The required duration for the consolidation by the $3 t$-method, as shown in Fig. 13, was satisfied in most cases. Since the pore water drainage was observed during the consolidation process, the specimens were partially saturated at the beginning of the axial compression process.

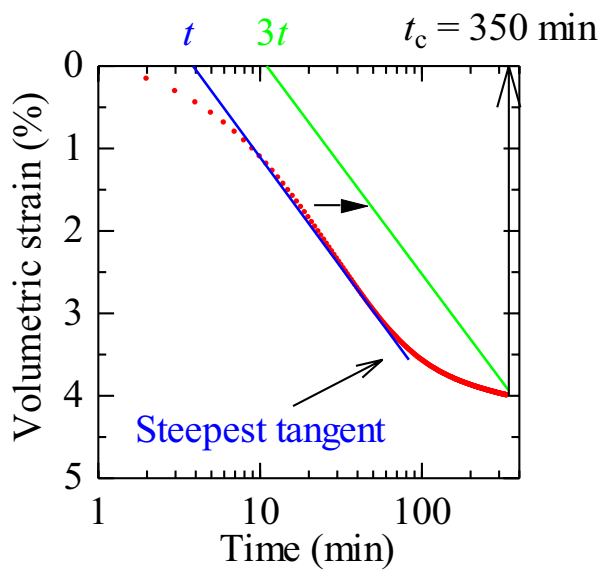

Fig. 13 Concept of 3t-method to estimate the required consolidation time tc (os42)

The same alternating strain rates as the uniaxial test were set for the axial compression. All specimens showed ductile, strain-hardening behaviors, as shown in Fig. 14 . The stress values at $6 \%$ axial strain were regarded as residual strength values and were used to estimate the parameter $n^{\prime}$ to represent the strain rate dependency in the residual strength. The calculated $n^{\prime}$-values from differential or total stress were almost identical to or higher than $n$-values by the uniaxial test, as shown in Fig. 15. Both $n^{\prime}$-values show weak positive correlations with the confining pressure. The friction angle for the residual strength was very low, $14.8^{\circ}$ for $10^{-5} \mathrm{~s}^{-1}$ and $15.6^{\circ}$ for $10^{-4} \mathrm{~s}^{-1}$. It is known that serpentinite consisting of brucite shows a low friction angle. Sakashita et al. [9] confirmed the friction angle decrease from $27^{\circ}, 26^{\circ}$, then $21^{\circ}$ in direct shear tests on the compacted quartz sand with 0,5 , or $10 \%$ brucite.

\subsection{Multistage creep}

The experimental setup and conditions were the same as the triaxial test at the alternating strain rates. The brittle creep failure (sudden strain increase or sudden stress drop beyond the control limit of the loading system) was not expected under confining pressure because the specimens yielded at around $1 \%$ axial strain, and the strain-hardening behavior followed in the alternating strain rate test as shown in Fig. 14. Therefore, the multistage creep test was carried out. The axial loading was carried out at a constant strain rate of $10^{-4} \mathrm{~s}^{-1}$, and the control mode was switched to a 24-h constant axial stress as the axial strain reached $0.5,1,2$, and $4 \%$ shown in Fig. 16a, b. These prescribed strain values were skipped if the strain exceeded them during the 24-h constant stress control. The eleven specimens showed only the primary creep shown in Fig. 16c, without 
Fig. 14 Examples of triaxial stress-strain curves. Red and blue lines denote the axial strain at $10^{-4} \mathrm{~s}^{-1}$ and 66 $10^{-5} \mathrm{~s}^{-1}$, respectively

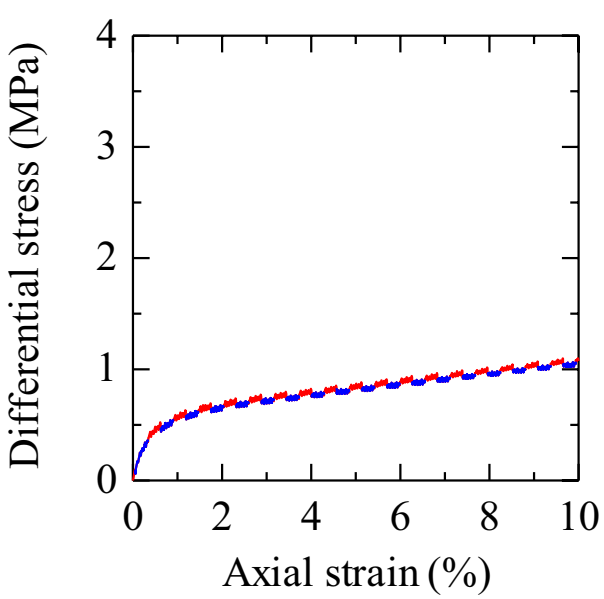

(a) $1.7 \mathrm{MPa}(\mathrm{os} 31)$

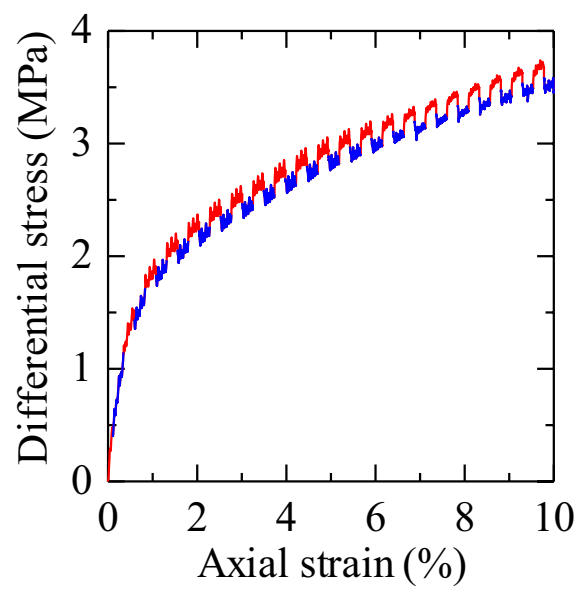

(c) $6.8 \mathrm{MPa}(\mathrm{os} 45)$

Fig. 15 The $n^{\prime}$-values from the alternating strain rate triaxial test

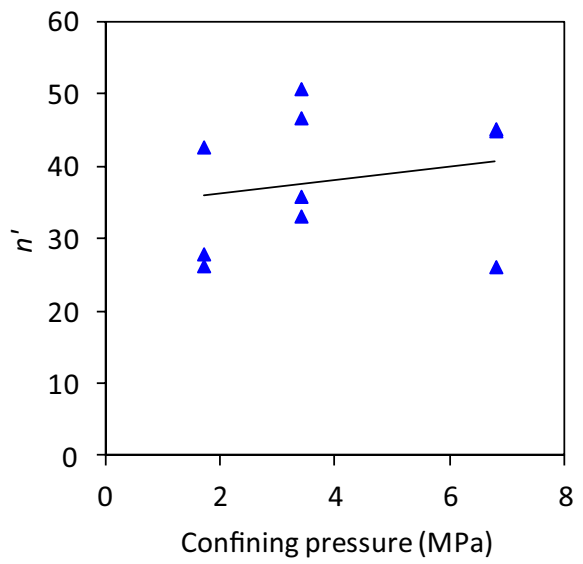

(a) Differential stress $(r=0.21)$

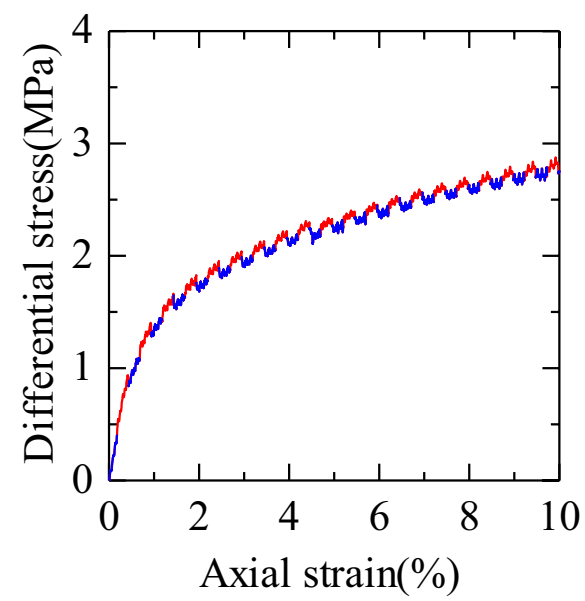

(b) $3.4 \mathrm{MPa}$ (os42)

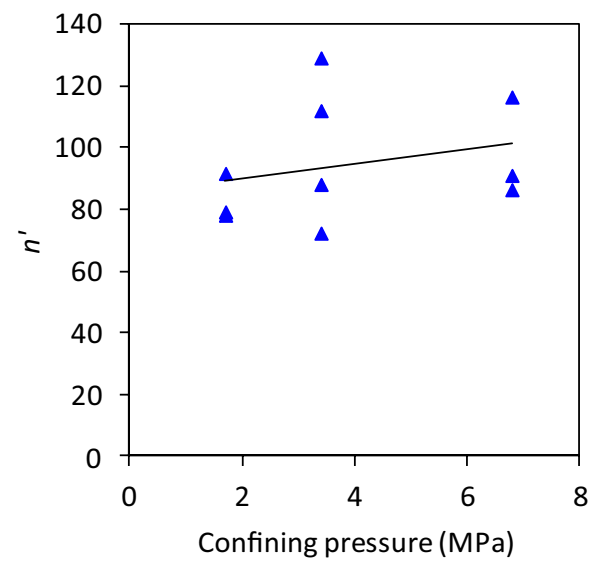

(b) Total stress $(r=0.27)$ 


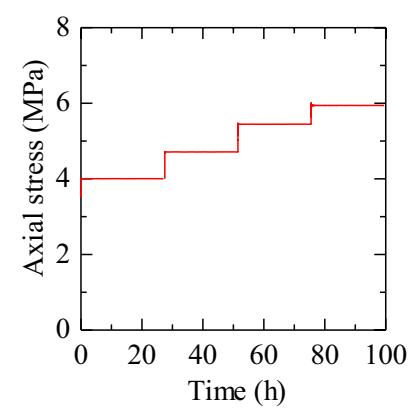

(a) Stress

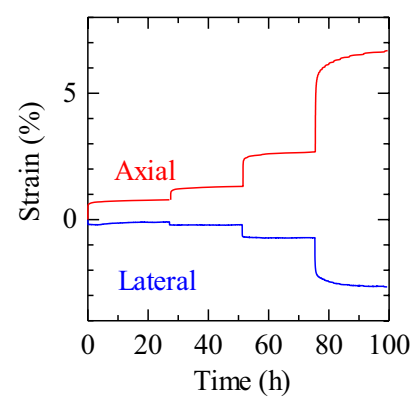

(c) Strains

Fig. 16 Example of the results of the triaxial creep test

secondary creep or creep failure. Therefore, the $n$ - or $n^{\prime}$ value can also be obtained as the slope of the log (creep stress)—-log (secondary creep rate) plot, was not observed.

\section{Discussions}

The observed deformation with severe damage shown in Fig. 4 resembles the primary, secondary, and tertiary creep behaviors. Therefore, the severe damage shown in Fig. 2 might be attributed to the serpentinite rock mass's significant time-dependent deformation and brittle creep failure. However, it should be noted that the damage had already begun in the New Year holidays. The monitored deformation curve is not the one that eventually leads to brittle creep failure. Moreover, the $n$-values for various rocks distribute between 10 and 80 [10], and the obtained $n$-values for the serpentinite are distributed within this range, as shown in Fig. 10. The $n$-value means that the serpentinite's time-dependent deformation is not extraordinarily large but rather the same as usual rocks. The triaxial creep behavior of the specimens also suggests that the serpentinite rock mass itself would not have shown brittle creep failure, as shown in Fig. 16.

Then, what would be the possible causes of the severe damage? Due to its extra-low strength shown in Fig. 8, the serpentinite rock mass in the tunnel's vicinity would have yielded entirely, regardless of any support. In this case, the effective active earth pressure without cohesion, $P_{2}^{\prime}$, may act on the serpentinite rock mass.

$P_{2}^{\prime}=\left(\frac{1-\sin \phi^{\prime}}{1+\sin \phi^{\prime}}\right) P_{1}^{\prime}$

where $P_{1}^{\prime}$ is the effective overburden pressure and $\phi^{\prime}$ is the friction angle for the residual strength. Shotcrete is subjected to both active earth pressure and pore pressure simultaneously. Assuming that the permeability of the shotcrete is much lower than that of the surrounding rock mass, the total external pressure $P_{2}$ can be

$P_{2}=P_{2}^{\prime}+P_{P}$

The maximum tangent compressive stress $\sigma_{\theta}$ appears at the inner wall of a thick-walled cylinder under external pressure $P_{2}$ as

$\sigma_{\theta}=\frac{2 P_{2}}{1-\left(\frac{r_{1}}{r_{2}}\right)^{2}}$

where $r_{1}$ and $r_{2}$ are the inner and outer radii of the cylinder. Substituting the effective overburden pressure of 3.4 $\mathrm{MPa}$ and the friction angle for residual strength of $15^{\circ}$ into Eq. (2), we get the effective pressure from shotcrete of $2.02 \mathrm{MPa}$. Substituting this pressure value and the pore pressure of $2.55 \mathrm{MPa}$ into Eq. (3), we get the total external pressure on the shotcrete of $4.57 \mathrm{MPa}$. Substituting $r_{1}$ and $r_{2}$ of $5.75 \mathrm{~m}$ and $6.35 \mathrm{~m}$ for the destructed first tunnel and $6.40 \mathrm{~m}$ and $7.55 \mathrm{~m}$ for the new tunnel with the total external pressure on shotcrete into Eq. (4), we get the maximum tangential compressive stress at the inner wall of the shotcrete of $51 \mathrm{MPa}$ and $32 \mathrm{MPa}$ for the old and new tunnels.

The shotcrete mixture ratio was designed to satisfy the strength of more than $36 \mathrm{MPa}$. Therefore, the former stress value would be enough to cause the creep deformation and brittle creep failure of shotcrete, even considering the reinforcement by the steel arches. The non-circular shape of the destructed tunnel also affects even to increase the stress of the shotcrete.

The mechanism of the successive tunnel failure can be considered as follows. The overburden depth increased with face advance, as shown in Fig. 1. The clayish portion ratio and the density of outfacing fractures whose dip was $\mathrm{ca} .30^{\circ}$ toward the face also increased [11]. Brittle creep failure of shotcrete may have occurred around the face during the New Year holidays in such a situation and would have been found as the damage. The active earth pressure to the rock mass decreased by the shotcrete failure. The yielding in the surrounding serpentinite rock mass around the failed shotcrete should have been enhanced by decreasing the confining pressure with the 
low friction angle by the brucite. The enhanced yielding may have increased the active earth pressure on the intact shotcrete next to the failed portion leading to a brittle creep failure. This successive brittle creep failure cycle may have continued for $400 \mathrm{~m}$ toward the entrance where the overburden pressure, the ratio of clayish serpentinite, and the outfacing fracture density became sufficiently low to stop the cycle.

\section{Concluding remarks}

A case of deformation at a serpentinite tunnel was described, and the mechanical properties of the serpentinite were experimentally investigated. It was clarified that the ratio of UCS to the estimated overburden pressure was astonishingly low in the range of $0.0047-0.057$. The friction angle was also very low and around $15^{\circ}$ by brucite. The serpentinite did not exhibit strong time dependency in deformation but exhibited rather similar time dependency to ordinary rocks. It was also found that the rock did not show brittle creep failure under triaxial compression.

The estimated pressure on the shotcrete from the rock mass for the damaged tunnel was enough to cause creep deformation and failure of shotcrete. Therefore, the severe damage to the tunnel would be caused by a successive brittle creep failure of shotcrete due to the creep deformation of the serpentinite rock mass rather than by a brittle creep failure of the serpentinite rock mass itself.

In the NATM (New Austrian Tunneling Method) construction, the surrounding rock mass is expected to support the rock stress. However, the expectation does not work in such a very weak rock mass, particularly it contains brucite and shows a very low friction angle. Designing the concrete lining which can support the earth and water pressure from the beginning would be much better than having severe damages and excavating again.

Authors' contributions YF: Supervision, Writing-Review and Editing, $\mathrm{NI}$ : Writing-Original Draft, YO, and YK: Investigation, TH: Data Curation, DA: Project Administration, JK, DF, AA, and AD: Writing-Review and Editing.

Funding This research received no external funding.

Availability of data and material Data can be obtained from the corresponding author upon request.

\section{Declarations}

Conflict of interest The authors declare that they have no conflict of interest.
Open Access This article is licensed under a Creative Commons Attribution 4.0 International License, which permits use, sharing, adaptation, distribution and reproduction in any medium or format, as long as you give appropriate credit to the original author(s) and the source, provide a link to the Creative Commons licence, and indicate if changes were made. The images or other third party material in this article are included in the article's Creative Commons licence, unless indicated otherwise in a credit line to the material. If material is not included in the article's Creative Commons licence and your intended use is not permitted by statutory regulation or exceeds the permitted use, you will need to obtain permission directly from the copyright holder. To view a copy of this licence, visit http://creativecommons. org/licenses/by/4.0\%.

\section{References}

1. Bai C, Xue Y, Qiu D, Su M, Ma X, Liu H (2021) Analysis of factors affecting the deformation of soft rock tunnels by data envelopment analysis and a risk assessment model. Tunn Undergr Space Technol 116:104111

2. Bizjak KF, Pekovšek B (2004) Displacement analysis of tunnel support in soft rock around a shallow highway tunnel at Golovec. Eng Geol 75:89-106

3. Ogawa O, Shimada T, Takahashi T (2020 in Japanese) Considering the excavation method at the serpentinite boundary of Otonaka tunnel, Annual Meeting of Hokkaido Regional Development Bureau.

4. Hashiba K, Okubo S, Fukui K (2006) A new testing method for investigating the loading rate dependency of peak and residual rock strength. Int J Rock Mech Min Sci 43(6):894-904

5. Atkinson BK (1984) Subcritical crack growth in geological materials. J Geophys Res 89(B6):4077-4114

6. Freiman SW (1984) Effects of chemical environments on slow crack growth in glasses and ceramics. J Geophys Res B6:4072-4076

7. Williams DP, Evans AG (1973) A simple method for studying slow crack growth. J Test Eval 1:264-270

8. Fujii Y, Kiyama T, Ishijima Y, Kodama J (1999) Circumferential strain behavior during creep tests of brittle rocks. Int J Rock Mech Min Sci 36(3):323-337

9. Sakashita T, Sasaki H, Horita Y (2015 in Japanese) Brucite content and strength characteristics of serpentinite, Annual Meeting of Hokkaido Regional Development Bureau.

10. Okubo S, Hashiba K, Fukui K (2013) Loading rate dependency of the strengths of some Japanese rocks. Int J Rock Mech Min Sci 58(6):180-185

11. Arakawa D, Nirei K, Konno S (2016 in Japanese) Damages by extraordinary earth pressure in serpentinite-Otonaka Tunnel, National Roadway No. 40, Otoineppu Village-, Annual Meeting of Hokkaido Regional Development Bureau.

12. Saito H, Kaketa K, Hashimoto T (2013 in Japanese) Construction report I, Consideration on tunnel support in serpentinite area, Annual Meeting of Hokkaido Regional Development Bureau.

Publisher's Note Springer Nature remains neutral with regard to jurisdictional claims in published maps and institutional affiliations. 